\title{
An Attempt to Introduce Neurological Test for Fetus Based on 3D and 4D Sonography
}

\author{
${ }^{1}$ Asim Kurjak, ${ }^{2}$ Badreldeen Ahmed, ${ }^{2}$ Salwa Abo-Yaquab, ${ }^{2}$ Moayyad Younis, ${ }^{2}$ Huda Saleh \\ ${ }^{2}$ Afaf Naim Shaddad, ${ }^{1}$ Oliver Vasilj, ${ }^{3}$ Awatif Juma AI Bahar, ${ }^{1}$ Berivoj Miskovic, ${ }^{2}$ Najat Khenyab \\ ${ }^{1}$ Department of Obstetrics and Gynecology, Medical School University of Zagreb, Sveti Duh Hospital, Zagreb, Croatia \\ ${ }^{2}$ Department of Obstetrics and Gynecology, Women's Hospital, Hamad Medical Corporation, Doha, Qatar \\ ${ }^{3}$ Department of Health and Medical Services, AI Wasl Hospital, Dubai, UAE
}

\begin{abstract}
Fetal neurology is a new challenging field. Brain damage often originates in fetal life. Early identification of this damage has implications for perinatal management; moreover documentation of such lesions is essential in case of litigation. In the last two decades, fetal imaging with 2-dimensional ultrasounds and conventional magnetic resonance imaging have made a major contribution in the identification of classic brain lesions and malformations. However, it is only recently with diffusion weight imaging that the whole spectrum of perinatal white matter injuries has been described in the neonate. The recent advances of 3DUS and 4DUS in exploring fetal motor behavior should support a better clinical description of the full spectrum of fetal damage. New neurological test (KANET) of the fetus recently suggested by us (Kurjak et al 2008) might be helpful in the assessment of fetal neurobehavior.
\end{abstract}

Keywords: Fetal neurology, 4D sonography, brain impairment.

\section{INTRODUCTION}

Fetal behavior could be described as any fetal action or reaction observed by the mother or other more objective method, as actocardiotocography or ultrasonography. Although more than 100 years of curiosity in fetal behavior and almost three decades of sustained awareness and research, the study of fetal behavior has not achieved widespread acceptance in perinatal medicine.

However, there is a growing pool of evidence that many neurological disorders originate from intrauterine rather than perinatal or postnatal period. Furthermore, clinical and epidemiological studies have shown that even cerebral palsy (CP) most frequently results from prenatal rather than perinatal or postnatal causes. ${ }^{14}$ Analysis of the dynamics of fetal behavior has led to the conclusion that fetal behavioral patterns directly reflect developmental and maturational processes of the fetal central nervous system. These findings implicated that understanding the relation between fetal behavior and developmental processes in different periods of gestation would make possible the distinction between normal and abnormal brain development, as well as the early diagnosis of various structural or functional abnormalities.

\section{THE ASSESSMENT OF FETAL NEUROBEHAVIOR}

Although there were numerous studies of embryonic and fetal behavior in the first trimester ${ }^{1-86}$ in this review we will concentrate on the second and third trimester.

\section{The Second Trimester}

Only a few studies are available on fetal movement patterns during the second trimester. ${ }^{15,35-40}$ De Vries and colleagues studied fetal movements from 20 and from 24 postmenstrual weeks onward. ${ }^{15}$ During the second trimester of pregnancy, the incidence of body movements increases considerably. The periods of quiescence become longer and eye movements are clearly visible with significant trends in fetal eye movement organization. ${ }^{38}$ The earliest eye movements appear at the developed by the end of the first trimester, indicating that some facial grimaces could appear at the 16th to 18th week of gestation, as do sporadic movements with a limited frequency. Isolated eye blinking patterns appear more frequently and begin to consolidate at the 24th to 26th week of gestation.

The incidence of hiccups startles and stretches decreased, whereas other movement patterns (jaw movement, hand-face contacts, and head movements) showed no clear developmental changes. ${ }^{36}$ At 28 postmenstrual weeks, Roodenburg and associates presented the following ranges and median values based on one-hour observations: jaw movements, 60-460, median 300; hand-face contact, 30-190, median 95; head rotations, 20-125, median 37; head retroflexions, 4-29, median $12 .{ }^{29}$ From a developmental point of view, one could say that in the second trimester the development continues, but there are no new movements appearing for the first time.

Spontaneous movements in fetuses from 12 to 35 weeks of gestation were described by Sparling and co-workers and they documented the typical hand movement. ${ }^{38}$ Many movements were shown to be straightforward, to a body part or uterine wall. The hands moved with different frequencies and force. Sparling also described repetition of head flexion movements, 
resulting in a 'sommersault' that makes possible for the fetus to change position within the uterine cavity throughout gestational ages. The fetuses' hands were extended and manipulated body parts and feature of the surroundings, for example, the umbilical cord. In a longitudinal study of fetal behavior from 14 weeks until neonatal period, Sparling and Wilhelm concluded that fetal and neonatal movements appeared to be directed to specific targets to the head and face. ${ }^{39}$ They stated that the most useful predictors of neonatal movement were the observations performed at 32 weeks of gestation.

After 12 weeks, GMs become more variable in speed and amplitude. We already know that most of the qualitative features of GMs are already present during the 4th to 5th months of gestation, with minor changes occurring in the last trimester of pregnancy.

Using 4D sonography, the Zagreb group have found that from 13 gestational weeks onwards, a "goal orientation” of hand movements appears and a target point can be recognized for each hand movement. ${ }^{40}$ According to the spatial orientation, the hand movements were classified into several subtypes: hand to head, hand to mouth, hand near mouth, hand to face, hand near face, hand to eye and hand to ear and its incidence were determined. The investigation included 25 fetuses in uncomplicated pregnancies; 15 fetuses at 13 to 16 weeks and 10 fetuses at 30 to 33 weeks of gestation. After standard assessment in 2D real-time B mode, a 4D mode was switched on and further examination lasted a maximum of 15 minutes. All recordings were performed between 14 and 17.30 hours, and no meals were taken within 2 hours of the beginning of the study. Patients with multiple or diabetic pregnancy at presentation were excluded from the study. In the first part of the study gestational age was determined using BPD measurement, while in the second part of the study gestational age was estimated from the first day of the last menstrual period and confirmed by the first trimester sonographic examination.

Isolated hand movement with subtypes of hand movements and facial activities with different forms of expression were easily recognized by 4DUS. All subtypes of hand to head movement could be seen from 13 weeks of gestation, with fluctuating incidence. Among facial expressions, two types could be easily differentiated: smiling and scowling. One could recognize that the amount of isolated arm movements decreased gradually from 13 to 16 weeks. The incidence varied between 50 and 120 with a median value of 60 at 13 weeks, 17 and 27 with a median value of 23 at 14 weeks, 0 and 6 with a median value of 2 at 15 weeks, 18 and 28 with a median value of 25 at 16 weeks. The highest range was registered at 13 weeks of gestation. The incidence of hand to head movement decreased, followed by a plateau at 14 weeks of gestation. The incidence varied from 4 to 29 at 13 weeks and from 0 to 7 at 16 weeks of gestation. The highest range of hand at mouth was found at 15 weeks of gestation, at 13 weeks a plateau was observed and with mild fluctuations the plateau continued until 16 weeks. The incidence varied between 0 and 4 with a median value of 2 at 13 weeks, and between 0 and 2 with a median value of 2 at 16 weeks. In contrast to most other movement patterns, hand near mouth movements decreased gradually from 13 weeks onwards with a single fluctuation in the 14th week. One can recognize that the incidence of hand near face movement is stable between 13 and 16 weeks of gestation with a slight increase at 14 and 15 weeks. At 13 weeks the range was the widest. The incidence of hand to ear movement showed a rapid trend of decrease between 13 and 16 weeks while the incidence of the hand to eye movement pattern showed the same developmental trend as the hand to head and hand to face movement patterns. ${ }^{42}$ The incidence varied between 4 and 12 with a median value of 8 at 13 weeks, and 0 and 3 with a median value of 0 at 16 weeks. The incidence of the hand to eye movement pattern showed the same developmental trend as the hand to head and hand to face movement patterns. At 13 weeks the incidence was between 4 and 12 occurrences per 15 minute observation time with a median value of 8 . At 16 weeks the range was from 0 to 3 with a median value of 1 . The authors concluded that 4DUS is superior over 2D real-time ultrasound for the qualitative, but inferior for quantitative analysis of hand movements. Thus, 4DUS makes it possible to determine exactly the direction of the fetal hand, but the exact number of each type of hand movements could not still be determined. The advantage of 4D over real time 2DUS is that isolated hand movements can be determined with confidence. Two-dimensional sonography easily recognizes hand movements associated with body movements, but there are problems in the recognition and differentiation of isolated hand movements and hand movements associated with leg movements. In this situation 4DUS is the method of choice for the reliable recognition of the isolated hand movements. Another advantage of 4DUS is the precise assessment of the direction of the hand movement and target of the fingers. Realtime 2DUS provides a tomographic image of the fetal head and visualizes hand movements in two dimensions. 4D sonography provides surface rendered images of the fetal head and visualization of hand movements in three dimensions that allows further differentiation of hand to head movements. ${ }^{40,41}$

In another study, the same group of authors confirmed that in the second trimester, the number of head and hand movements decreased gradually compared with the first trimester. The highest incidence was registered for head retroflexion pattern, with range of 15 to 42 and median of 25. Among facial expressions, the highest incidence was found for sucking, with the range between 3 and 30 and median of 9. ${ }^{42}$

Kuno and co-workers evaluated fetal behavioral patterns in the early second trimester in 11 healthy pregnant women at 14 to 18 weeks of gestation and they found that the most active fetal behavioral pattern was arm movement in each fetus, whereas the least active was mouth movement. Each fetal 
movement was synchronized and harmonized with other fetal movements during this period of pregnancy. ${ }^{36}$

Kurjak et al reported the first study with the 4DUS techniques used for obtaining longitudinal standard parameters of fetal neurological development in all trimesters of a normal pregnancy. ${ }^{43}$ Valid reference ranges appropriate for gestational ages are essential for comparisons with former or future measurements of patients. For that purpose a group of 100 healthy normal singleton pregnancies were recruited for longitudinal 4DUS examinations to evaluate fetal neurodevelopmental parameters between 7 to 40 weeks' gestation. The patients were assigned to the study if they met inclusion criteria, if the fetus and the mother were considered "normal", 2D ultrasound and clinical assessment were uneventful and if the neonates, eventually delivered at term, had normal 1- and 5- min Apgar scores. Pregnancies that were subsequently found to be complicated by congenital abnormalities, gestational diabetes, and hypertensive disorders in pregnancy, preterm deliveries, and abnormal Apgar scores were excluded. Those fetuses from the 2nd and the 3rd trimester whose examined parts of the body were not able to be visualized in one region of interest were also excluded from the study. In the first trimester 8 fetal movement patterns were analyzed and 14 parameters of fetal movement and fetal facial expression patterns recorded thereafter for the construction of fetal neurological charts. Standard parameters of fetal movements and facial expressions in all trimester of pregnancy are presented in Figures 1 and 2.

The statistical analysis of the incidence of fetal movements and facial expressions studied in the first trimester revealed statistically significant changes in general movements, stretching, isolated arm and leg movement, head retroflexion, head rotation and head retroflexion (Figs 3A to $\mathrm{H}$ ).

At the first trimester, a tendency towards increased frequency of fetal movement patterns with increasing gestational age has been noticed. Only in the startle movement
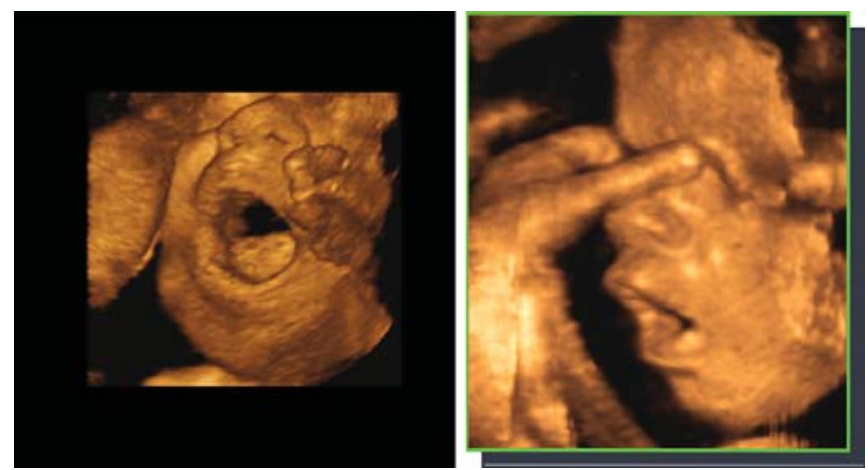

Fig. 1: Fetal yawning assessed by three-dimensional (3D) ultrasound. This movement includes prolonged wide opening of the jaws followed by quick closure, often with retroflexion of the head and sometimes elevation of the arms. This movement pattern is non-repetitive and it appears around 11 th week
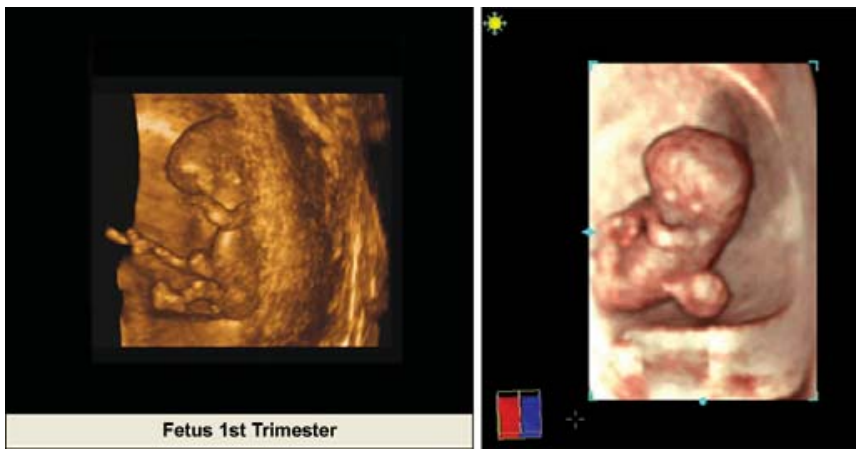

Fig. 2: 3D surface rendering mode of the fetus in the first trimester which enables the visualization of the whole fetal body with the possibility of 4D motility assessment. Embryonic and human facial development can be investigated during the first trimester by 3DUS surface rendering mode.

pattern, it seemed to occur stagnantly during the first trimester (Fig. 1B).

In this type of movement, there was no significant correlation with gestational age, as shown by the large dispersion of scatter points around the regression line ( $\mathrm{r} 0.673$; P 0.506). At the first trimester, a tendency towards increased frequency of fetal movement patterns with increasing gestational age was noticed. During the 2nd and the 3rd trimester, multiple regression and polynomial regression revealed statistically significant changes in tongue expulsion, grimacing, swallowing, head movements, and all hand to body contact movements $(\mathrm{P}<0.05)$ (Figs 4A to $\mathrm{N}$ ).

The authors found a tendency towards an increase in the frequency of fetal movement patterns at the beginning of the 2nd trimester. They noticed fluctuation and dispersion of the incidence of all facial expressions as seen in the polynomial regression diagram (Figs $4 \mathrm{~A}$ to $\mathrm{N}$ ). All types of facial expressions display a peak frequency at the end of the 2nd trimester, except in isolated eye blinking which increases at the beginning of 24th week. At the beginning of the third trimester, the fetuses display decreasing or stagnant incidence of fetal facial expression. However, all types of head movements and hand to body contact movements indicated a decrease in frequency from the beginning of the 2nd trimester to the end of the 3rd trimester. This longitudinal study establishes reference ranges with gestational age for suggestible used fetal neurobehavioral development parameters in respected number of normal singleton pregnancies. Standard of movement pattern and facial expression pattern curves are constructed through all the trimesters of pregnancy. Results from Yigiter and Kavak are similar to that study, as they found a significant correlation between all head movements and hand to body contact patterns during the 2nd and the 3rd trimesters except for head anteflexion, which did not show a significant change during the second half of pregnancy. ${ }^{34}$ It has also been suggested that there is a tendency towards decreased frequency of observed facial 
Asim Kurjak et al
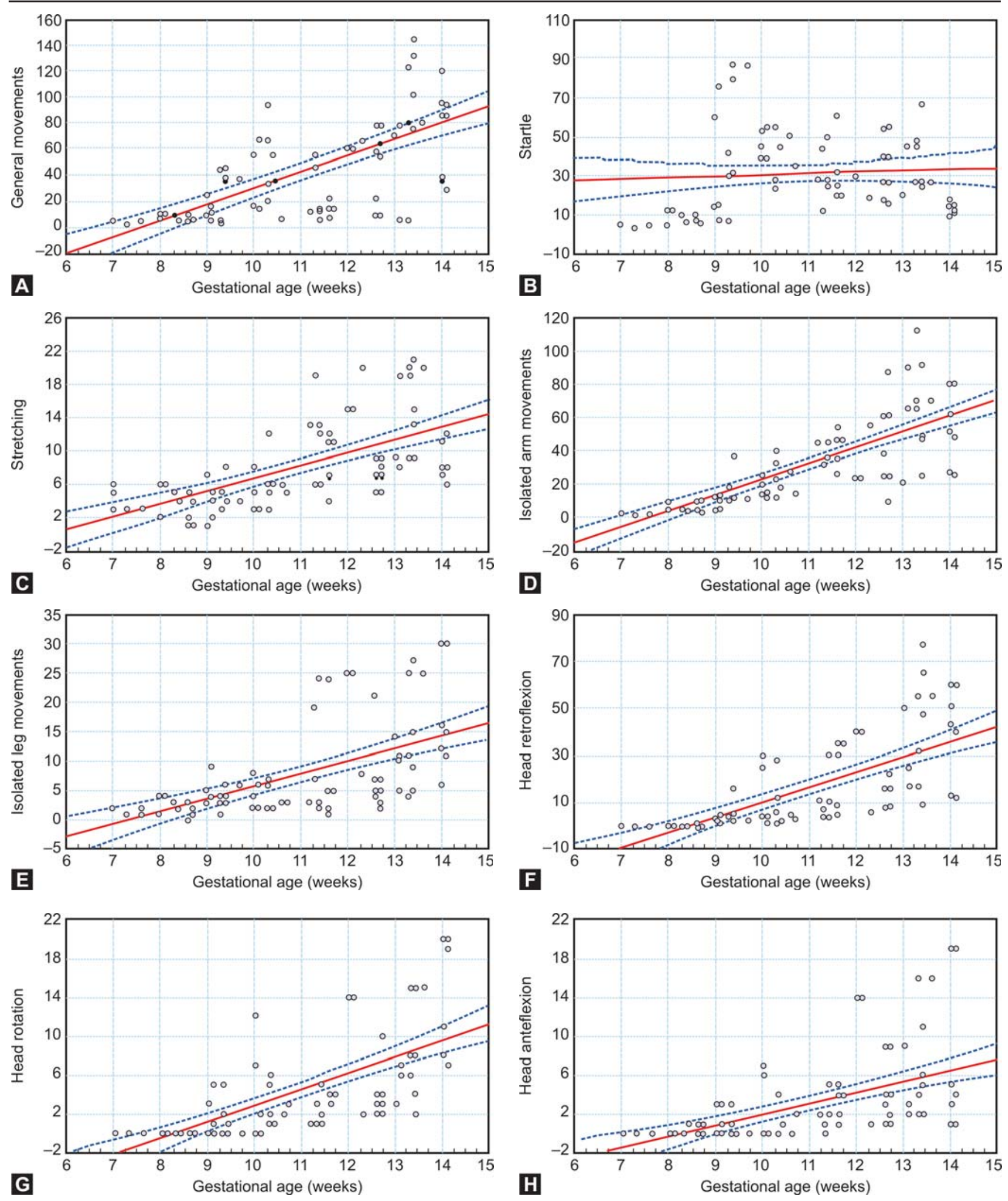

Figs 3A to H: Scatter plot and multiple regression analysis of the first trimester frequency of: (A) general movements, (B) startle, (C) stretch, $(D)$ isolated arm movement, $(E)$ isolated leg movement, $(F)$ head retroflexion, $(G)$ head rotation, $(H)$ head anteflexion 

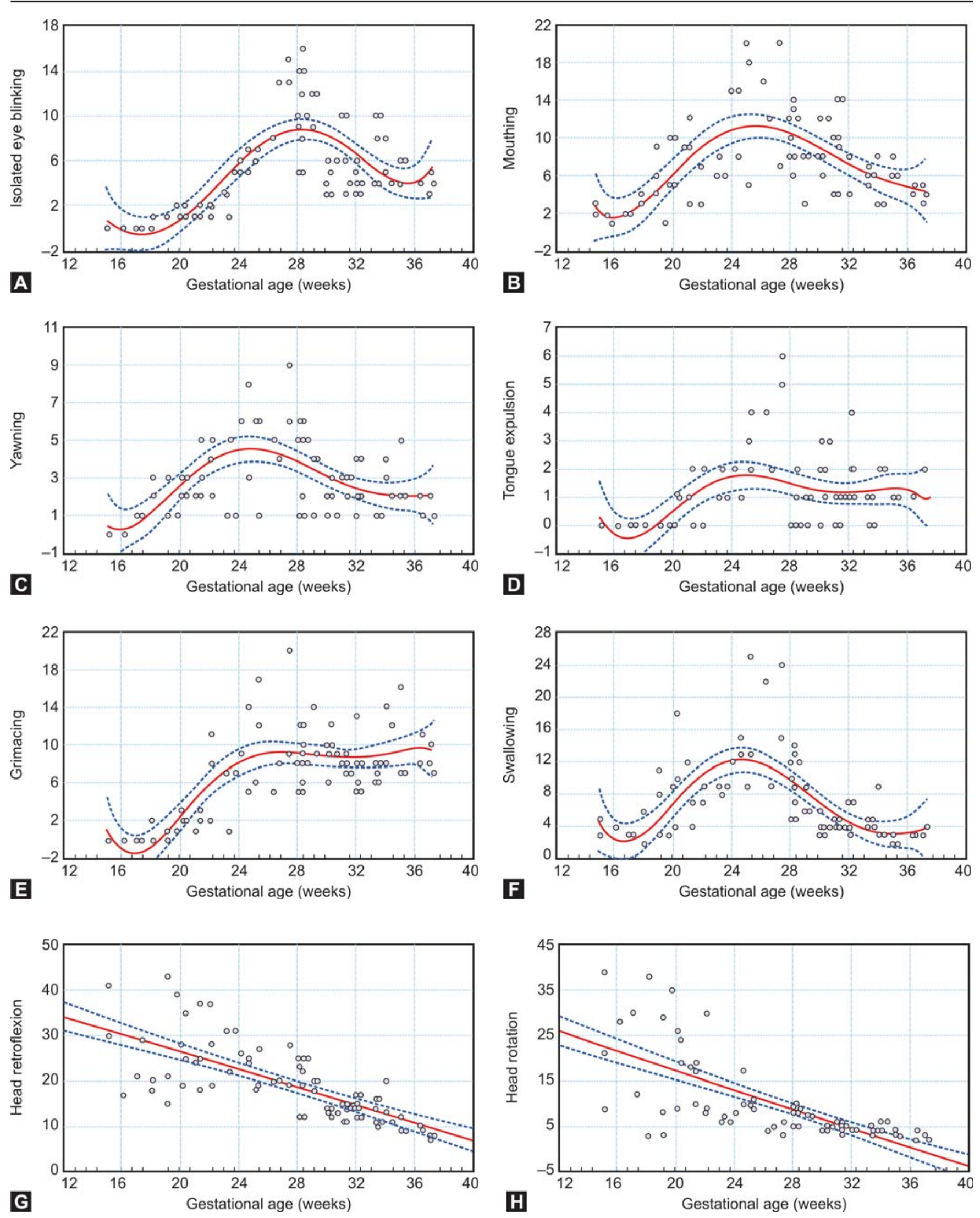

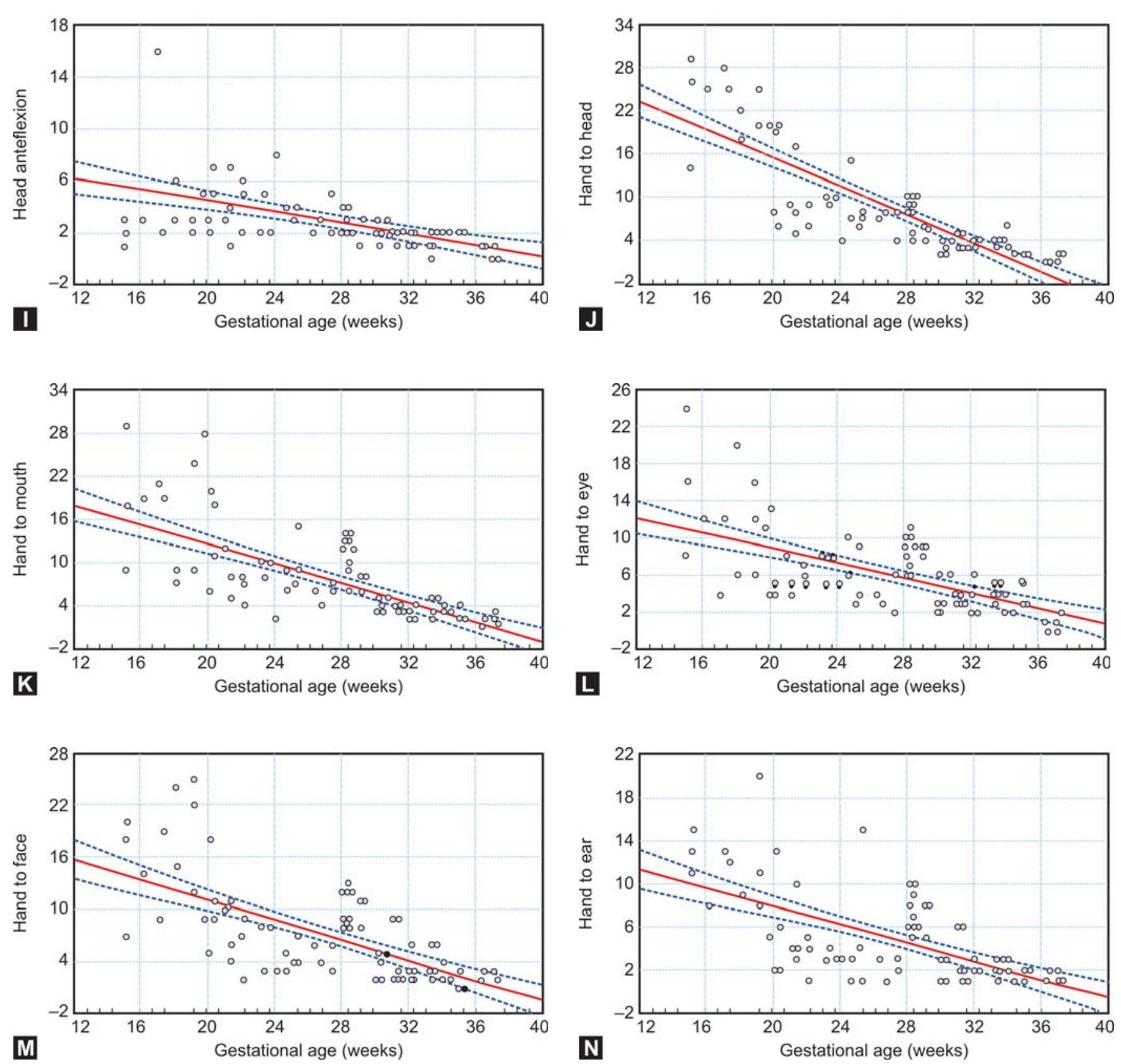

Figs 4A to N: Scatter plot and multiple regression analysis of the 2nd to 3rd trimesters frequency of: $(A)$ isolated eye blinking, $(B)$ mouthing, (C) yawning, (D) tongue expulsion, $(E)$ grimacing, $(F)$ swallowing, $(G)$ head retroflexion, $(H)$ head rotation, $(I)$ head anteflexion, $(J)$ hand to head, $(\mathrm{K})$ hand to mouth, $(\mathrm{L})$ hand to eye, $(\mathrm{M})$ hand to face, $(\mathrm{N})$ hand to ear

expressions and movement patterns with increasing gestational age. ${ }^{43}$ All types of facial expressions display a peak frequency at the end of the 2nd trimester, except in isolated eye blinking which increases at the beginning of 24th week. ${ }^{43}$

\section{The Third Trimester}

During the second half of pregnancy, motor behavior becomes increasingly frequent and variable. Patrick and colleagues studied ultrasonically fetal stretching and rolling movements during the last 10 weeks of pregnancy and found that fetuses on average made 31 gross fetal body movements per hour which accounted for $10.2 \%$ of time. ${ }^{44}$ In a behavioral study of 20 healthy preterm infants (gestational age from 28 to 34 weeks), an obvious developmental improvement in orienting responses and in motor performance was assessed. ${ }^{44}$ Prechtl and colleagues showed that the development was intraindividually characteristic and 
consistent, but interindividually variable. ${ }^{45}$ In short, a rich variety of fetal and premature movements has been described and it has been shown that the repertoire of fetal movements consists exclusively of motor patterns which can also be observed postnatally and that there is a high degree of continuity of behavior before and after birth. However, the newborn's behavioral repertoire rapidly expands with patterns never observed in the fetus, such as the Moro response. Significant developmental changes in specific movement patterns during the last trimester of pregnancy are in eye movements: isolated eye movement was observed since the 16th week of gestation and rapid eye movements since the 19th week. ${ }^{46}$

The parameters that could be detected and analyzed during the 3rd trimester are fetal heart rate pattern, and eye and body movements. ${ }^{13}$ The association of these movements increases steadily and, in the last weeks of pregnancy, fetal behavior can almost completely be described in terms of behavioral states, which are stable over time and recur repeatedly, not only in the same infant, but also in similar forms in all infants..$^{17,47,48}$ The concept of behavioral states has been used as a descriptive categorization of behavior, and also as an explanatory concept in which states are considered to reflect particular modes of nervous activity that modify the responsiveness of the infant. ${ }^{17}$

By term, normal number of generalized movements per hour was found to be approximately 31 with the longest period between movements ranging from 50 to 75 minutes. ${ }^{15}$ This reduction is considered as a result of cerebral maturation processes, rather than a consequence of the decrease in the amniotic fluid volume. Simultaneously with the decrease in the number of generalized movements, an increase in the facial movements, including opening/closing of the jaw, swallowing and chewing can be observed. These movements can be seen mostly in the periods of absence of generalized movements and that pattern is considered to be the reflection of the normal neurological development of the fetus. ${ }^{15}$ However, not only the changes in the quantity of movements, but also in their quality are shown to be the result of maturational processes.

The incorporation of 3DUS technology into clinical practice has resulted in remarkable progress in visualization and anatomic examination of the fetal face. 4DUS, in turn, provided for the first time an opportunity to evaluate subtle fetal facial expressions, which can be used to understand fetal behavior. ${ }^{49}$ 4DUS has additional advantages in studying fetal activity in the surface rendered mode and is particularly superior for fast fetal movements. Because of its curvature and small anatomic details, the fetal face can be visualized and analyzed only to a limited extent with 2DUS ${ }^{5}$ (Fig. 5).

The entire face cannot be seen on a single 2DUS image, but 3DUS allows spatial reconstruction of the fetal face and simultaneous visualization of all facial structures such as the

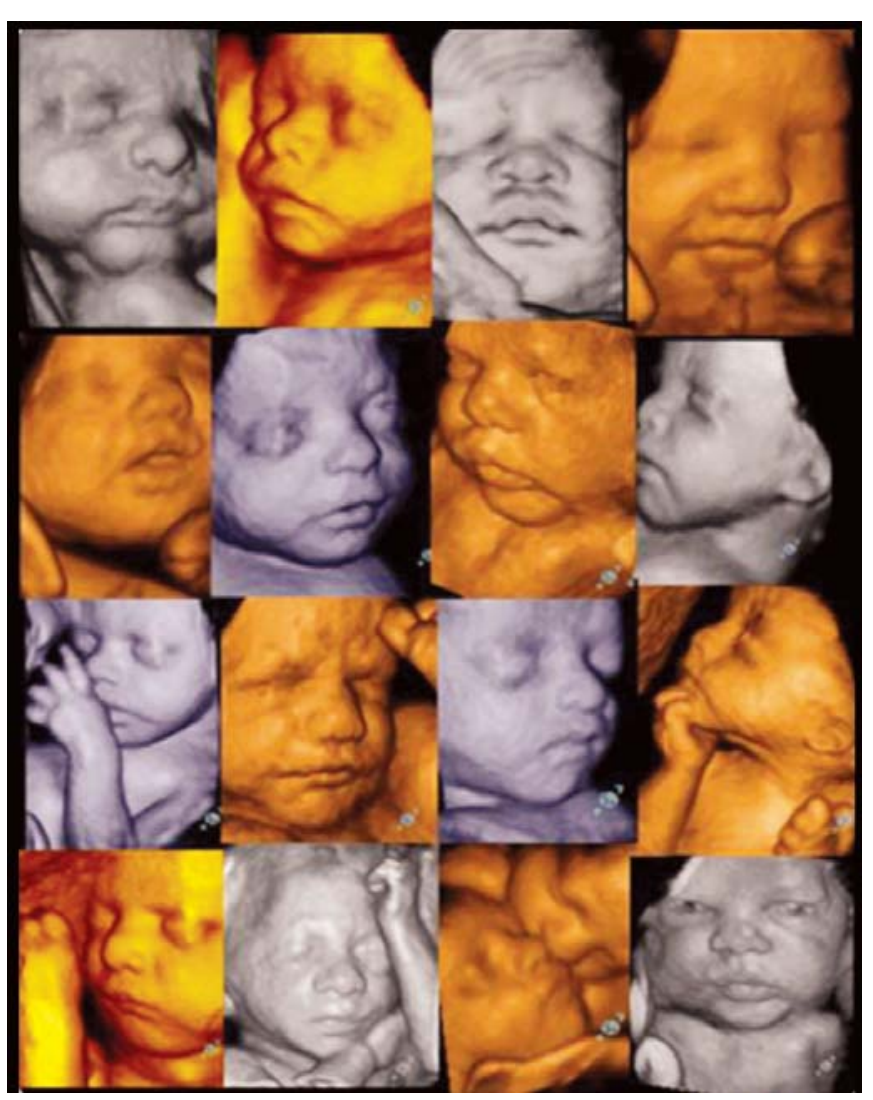

Fig. 5: 3D surface rendering mode of the different fetal facial expressions in the third trimester. This ultrasound mode enables the investigation of behavioural fetal facial expression

fetal nose, eyebrows, mouth, and eyelids. The standardized image display helps sonologists to understand fetal anatomy better and to communicate complex observations to both parents and less-experienced observers. This technique does not replace conventional real-time 2DUS imaging, but rather supplements it. 3DUS requires an investment of additional time in each case; therefore, it is predominately used, presently in conjunction with 2DUS, as a problem-solving tool.

Although facial movements, which are controlled by $\mathrm{V}$ and VII cranial nerves, appear around 10 and 11 weeks, the exact onset of facial expressions has not been determined and it is still unclear whether their appearance is gestational age related. ${ }^{49}$ The possibility of studying such subtle movements might open a new area of investigation.

Simultaneously with the decrease in the number of general movements, an increase in facial movements, including opening or closing of the mouth and swallowing, can be observed. This pattern is considered to be a reflection of the normal neurological development of the fetus. An important diagnostic aim of the observation of facial expression is prenatal diagnosis of facial paresis. The criterion for the diagnosis is asymmetric facial movement and detection of the movement's limited to only one 
side of the face. Unfortunately, during the relaxed phase it is not possible to evaluate the status of the facial nerve. Therefore, during the active phase, the fetus should be scanned by 4DUS. Because the origin of facial expression can be influenced by external forces, before the final diagnosis, examiners should be aware of this pitfall. For example, force of the fetal hand can alter the facial expression on one side of the face, causing asymmetry. This kind of asymmetry, however, should be differentiated from pathologic features such as unilateral facial paresis. $^{49}$

Zagreb group evaluated fetal behavioral patterns in the 3rd trimester between 30 and 33 weeks of gestation in ten gravidas. ${ }^{41}$ The incidence of eyelid movements ranged between 4 and 20 with a median value of 17 , mouthing movements ranged between 2 and 19 (Fig. 6) with a median value of 12, and mouth and eyelid movements ranged between 0 and 13 with a median value of 5 .

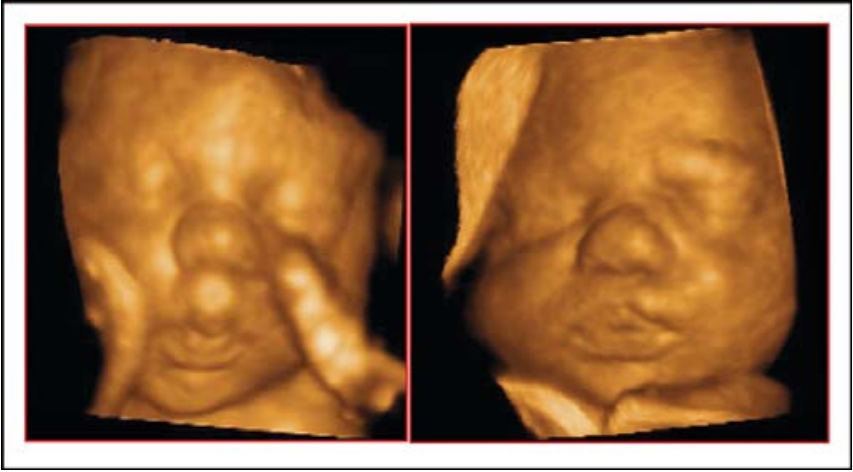

Fig. 6: 3D surface rendering mode of the fetal mouthing in the third trimester

\section{Mouthing Movements Dominate at this Gestational Age}

The incidence of pure mouth movement such as mouth opening ranged between 4 and 13 with a median of 5, tongue expulsion (Fig. 7) ranged between 0 and 2 with a median of 2, yawning ranged between 0 and 2 with a median of 1, and pouting ranged between 0 and 9 with a median of 3 .

The incidence of facial expressions such as smiling ranged between 2 and 7 with a median of 2, and scowling between 2 and 4 with a median of 2 . It is evident that eyelid and mouthing movements dominate at this gestational age. ${ }^{40}$ Pure mouth movements such as mouth opening, tongue expulsion, yawning and pouting are present, but at a significantly lower incidence. Facial expressions such as smiling (Fig. 8) and scowling can be observed.

Surface rendered images that were used in this study depict the entire face and the relationship between facial structures such as the nostrils, opened or closed eyelids and mouth on a single image. Furthermore, depiction and observation of the

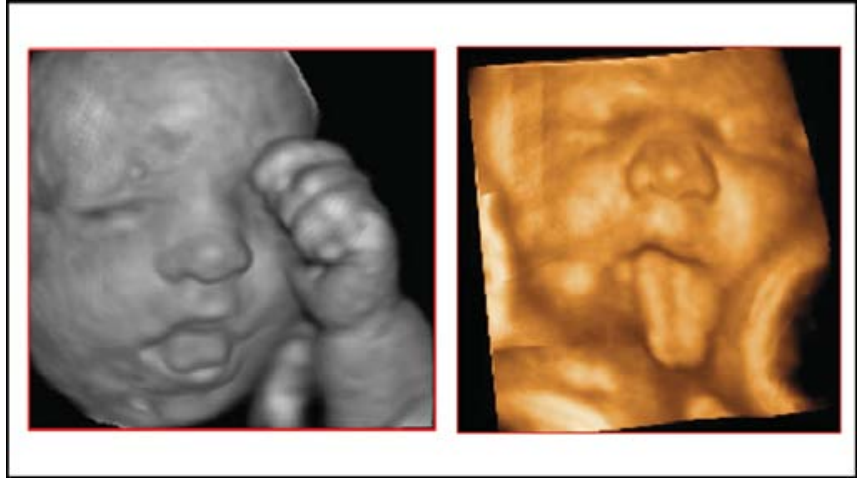

Fig. 7: 3D surface rendering mode of the fetal tongue expulsion in the third trimester

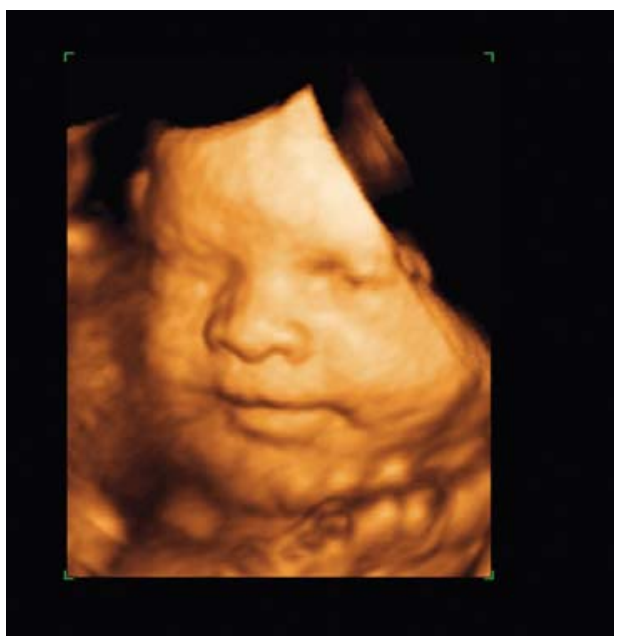

Fig. 8: 3D surface rendering mode of the fetal smiling in the third trimester. This movement is shown to have the continuity in its incidence in the neonatal period

orbital region and the status of fetal eyelids can be easily performed by this mode. However, eye movement cannot be registered because of the character of 4DUS that allows visualization exclusively of superficial structures such as the eyelid. Simultaneous visualization of eye movement and mouthing can therefore not be achieved. The focus of interest in that study was the analysis of eyelid movements and mouthing both separately and together. Since there is a relationship between mouthing and non-rapid eye movement phases the group of authors hypothesized that non-rapid eye movement phase's correlate with closed eyes and mouthing phenomenon, and that this pattern can be indirectly determined by 4DUS. Using 3DUS it was not possible to determine the beginning of mouth opening or smiling or the beginning of mouth opening, mouthing or yawning. Therefore, 3DUS is not suitable for the observation of facial expression. Furthermore, as well as the duration of single facial movement or expression, complex facial movements such as the simultaneous movement of the two 
facial organs mouth and eyelid can be depicted. Mouthing, mouth opening and yawning simultaneous with eyelid opening can thus only be seen using 4DUS.

The next study by this team showed the ability of $4 \mathrm{D}$ sonography to depict different facial expressions and grimacing (Fig. 9), which might represent fetal awareness. ${ }^{52}$
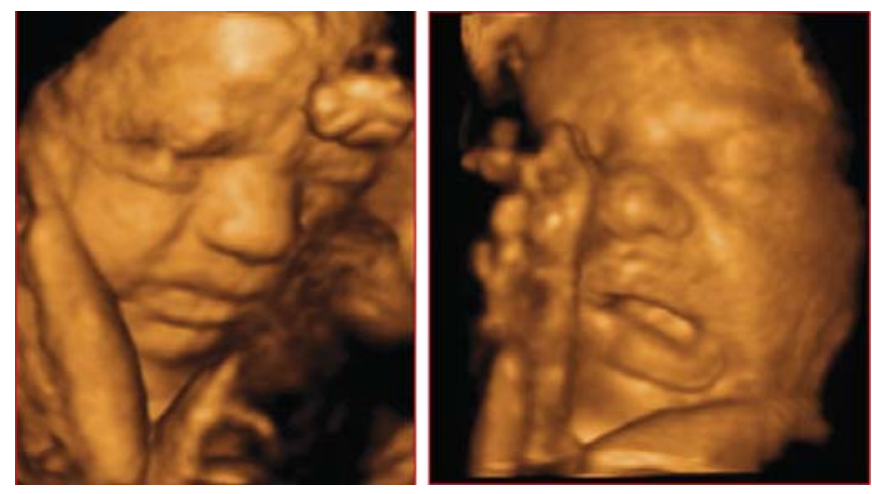

Fig. 9: 3D surface rendering mode of the fetal grimacing in the third trimester. This movement is shown to have the continuity in its quantity and quality in the neonatal period

This was based on the consideration that "the face predicts the brain" because of the same embryologic origin for many facial and encephalic structures. ${ }^{53}$ Very early in pregnancy fetuses are reactive to stimuli, but the reaction does not provide any evidence that the fetus actually experienced the stimulus. It has been shown that noxious stimuli can initiate physiological, hormonal, and metabolic responses, but these neither imply nor preclude suffering, pain, or awareness. Is it the facial expressions of the fetus that can help to understand what the fetus would like to communicate? We can see on the fetal face whether it is satisfied or unhappy, smiling or worried, selfconfident or uncertain, but it is questionable whether the expression of the fetal face predicts its normal neurological development. Whether the fetal face is an "organ that expresses awareness" with very complex functions is still questionable, because we need more scientific confirmation of what constitutes fetal awareness.

The study included 99 patients, 40 of whom were in the second and 59 in the third trimester of pregnancy. Positive observation has been defined as a facial expression or movement noted at least once during the observation of one examinee. A tendency towards increased frequency of observed facial expressions with increasing gestational age was noted, but the difference between second- and third-trimester fetuses was not significant due to the low frequency of movements. As at that time the images were only near real-time, they were only able to study the quantity and not the quality of facial movement patterns with the possibility that some very subtle facial movements may have been missed.
In the recent study by Yan and his group, 10 healthy fetuses aged from 28 to 34 weeks were recorded continuously for 15 minutes with a 4D ultrasonographic machine and the occurrence rates of blinking, mouthing, yawning, tongue expulsion, smiling, scowling, and sucking were evaluated. ${ }^{54}$ As in previous reports mouthing was found to be the most active facial expression during this gestational period. ${ }^{41,52}$ However, the frequency of blinking was lower in this study. This could be due to the differences in the characteristics of the samples recruited and differences in interpreting the definition of each facial expression.

During the last trimester of pregnancy, significant developmental changes in specific movement patterns can be observed. Isolated eye movements can be registered from 16 gestational weeks onwards and rapid eye movements from 19 weeks. ${ }^{55}$ The eye movement patterns begin to consolidate at 24 to 26 weeks of gestation, and the periods of eye movements (EM) begin to alternate with non-eye movement periods (NEM). During the last 10 weeks of gestation, both switching and maintaining mechanisms responsible for this ultradian rhythms mature, and constant mean values of duration of EM and NEM periods are achieved by 37 to 38 weeks. At that time, EM and NEM lasted 27 to 29 and 23 to 24 minutes respectively, which is similar to the values in the neonate. ${ }^{56}$ From 33 weeks onward, both rapid eye movement (REM) pattern and slow, rolling movement (SEM) pattern can be registered, and the periods of REM alternate with periods of NEM. At 36 to 38 weeks of gestation, they become integrated with other parameters of fetal activity, such as heart rate and fetal movements, into organized and coherent behavioral states. ${ }^{7,57}$ This indicates that the pontine and thalamocortical connection area neurons start functioning at that time. Regular mouthing concurred closely with the non-rapid eye movement period from 35 weeks to term, whereas random mouthing movement was observed predominantly during the eye-movement period and was unrelated to the advance of gestational age. ${ }^{41}$

\section{New Scoring System for Fetal Neurobehavior Based on 3D and 4D Sonography}

In the recent study, the Zagreb group attempted to produce a new scoring system for fetal neurobehavior based on prenatal assessment by 3D/4D sonography (KANET). ${ }^{82}$ KANET is a combination of some parameters from fetal GM assessment and parameters from postnatal ATNAT which can be prenatally easily visualized by 4DUS. ${ }^{83,84}$ The parameters were chosen basing on developmental approach to the neurological assessment and on the theory of central pattern generators of GM emergence (Figs 10 to 15).

They were the product of multicentric studies conducted during several years which resulted with the most significant parameters for the assessment of fetal neurological develop- 


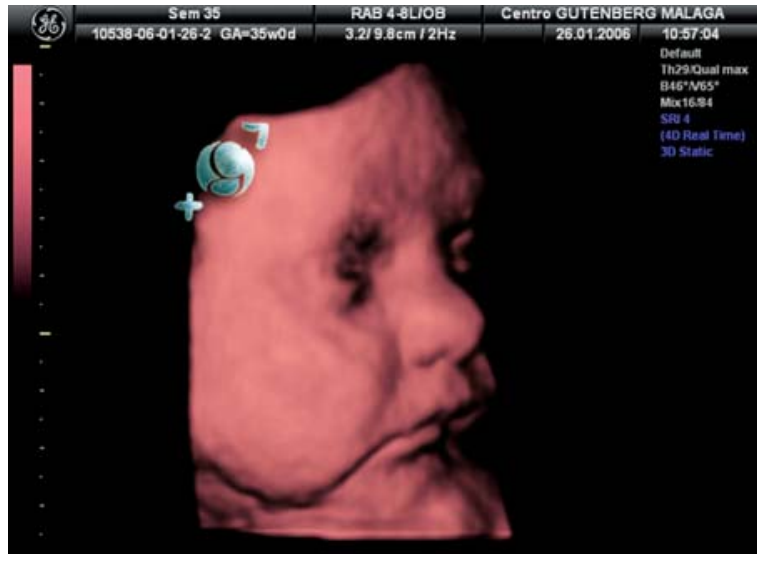

Fig. 10: Isolated fetal eye blinking as a sign for neurological test. It is described as being fluent if repeated more than 5 times and not fluent if repeated less than 5 times

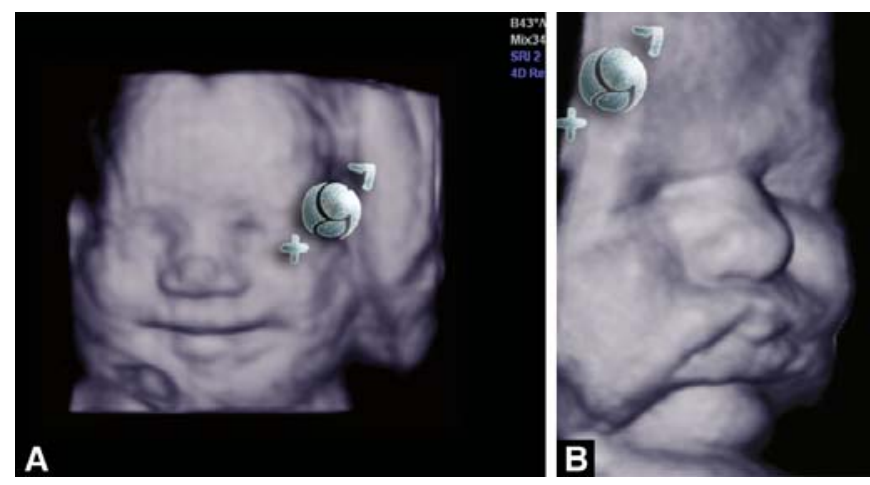

Figs $11 \mathrm{~A}$ and $\mathrm{B}$ : Isolated fetal grimacing as a sign for neurological test: (A) smiling, (B) scowling

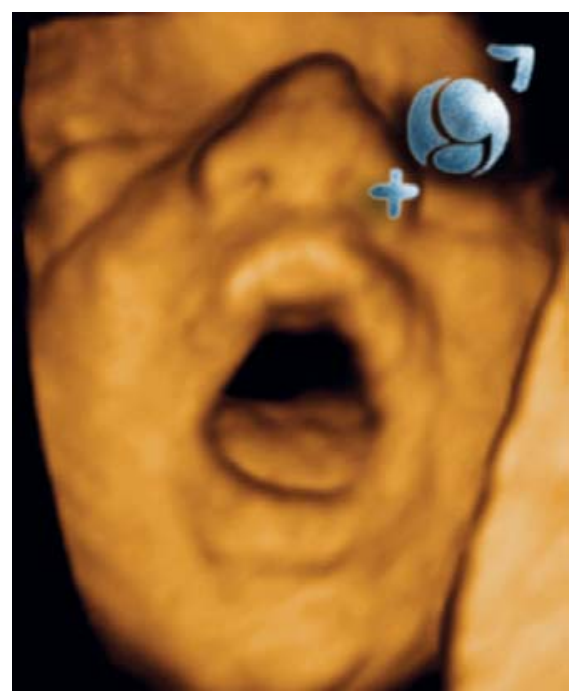

Fig. 12: Isolated fetal mouth opening as a sign for neurological test. It is described as being fluent if altered more than 3 times and not fluent if repeated less than 3 times

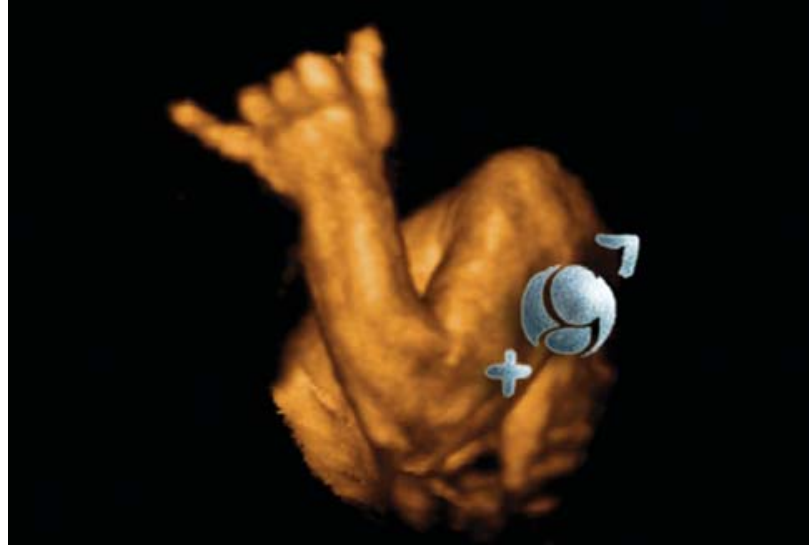

Fig. 13: Isolated hand movement as a sign for neurological test. These movements can be qualified as being of poor repertoire, cramped or variable and complex

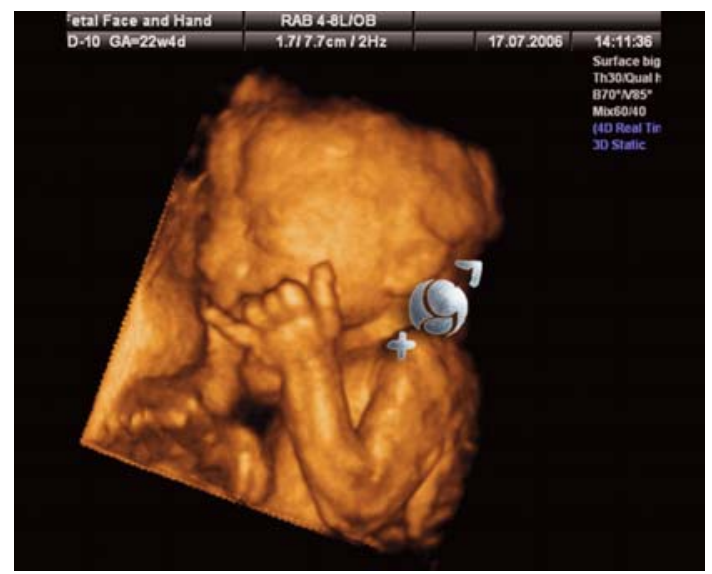

Fig. 14: Fetal hand to face movement as a sign for neurological test. These movements can be qualified as abrupt, variable in full range with many alternations (more than 6 ) or can have small range

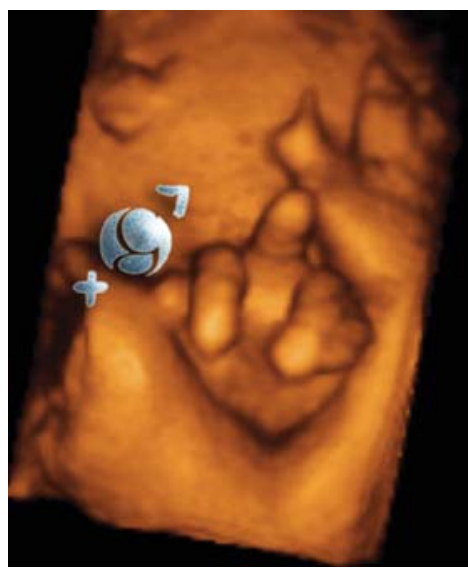

Fig. 15: Isolated finger movement as a sign for neurological test. These movements can be cramped, invariable finger movements or smooth and complex, variable finger movements. Unilateral or bilateral clenched fist are described as neurological thumb 
ment. $^{42,43,64}$ The authors developed a three-point scale for isolated head anteflexion, isolated hand, leg, hand to face and finger movements, while for the assessment of cranial sutures, isolated eye blinking, facial alterations and mouth opening twopoint scale was applied. The distinction between scores 0 and 2 is evident, whereas uncertainty may exist with regards to the assignation of a score of 1 , the latter indicating an abnormal result of moderate degree. The precise description of the moderate abnormal performance is included for each item in the record form as well as interpretation of total score.

To produce the new scoring test the Zagreb group identified severely brain damaged infants and those with optimal neurological findings by comparing fetal with neonatal findings. In the group of 100 low-risk pregnancies they retrospectively applied new scoring system. After delivery, postnatal neurological assessment (ATNAT) was performed, ${ }^{67}$ and all neonates assessed as normal reached a score between 14 and 20 , which was assumed to be a score of optimal neurological development. New scoring system was applied in the group of 120 high-risk pregnancies in which, based on postnatal neurological findings, three subgroups of newborns were found: normal, mildly abnormal or moderately abnormal. Based on this, a neurological scoring system has been proposed. All normal fetuses reached a score in the range from 14 to 20. Ten fetuses who were postnatally described as mildly or moderately abnormal achieved prenatal score of 5 to 13, while another ten fetuses postnatally assigned as neurologically abnormal had a prenatal score from 0 to 5 . Among this group four had alobar holoprosencephally, one had severe hypertensive hydrocephaly, one had tanatophoric dysplasia and four fetuses had multiple malformations.

We propose that test should be called KANET (Kurjak et al antenatal neurological test). That was a preliminary study that will continue in several collaborative centers. It is hoped that the future database formed using this new score for fetal neurological assessment will help in distinguishing fetal brain and neurodevelopmental alternations due to the early brain impairment occurring in utero. Study of a large population will hopefully validate the value of the new test as a predictive marker for fetal neurodevelopmental outcome in both low-risk and high-risk populations.

The inclusion criteria are represented in Table 1.

Table 1: Inclusion criteria

\begin{tabular}{ll}
\hline Family history & $\begin{array}{l}\text { Previous child with cerebral palsy } \\
\text { Maternal condition }\end{array}$ \\
Fetal condition & $\begin{array}{l}\text { preeclampsia, viral illness, intrauterine infections } \\
\text { Structural anomalies, limb contractures, facial } \\
\text { anomalies, subcutaneous edema, intrauterine growth } \\
\text { restriction } \\
\text { Pajor infarction, thrombotic vasculopathy, tight } \\
\text { cord pathology }\end{array}$ \\
Psychological factors & $\begin{array}{l}\text { Maternal anxiety caused by abnormal fetal } \\
\text { movements }\end{array}$ \\
\hline
\end{tabular}

The description and the meaning of each specific movement and sign is described in Table 2.

The KANET is presented in the Table 3.

Table 2: The description and the meaning of each specific movement and sign in KANET

\begin{tabular}{|c|c|c|}
\hline Parameter & Observation & Significance \\
\hline Isolated anteflexion of the head & $\begin{array}{l}\text { Normal } \\
\text { This movement not associated with GMs. Usually carried } \\
\text { out slowly, but they can also be fast and jerky } \\
\text { Abnormal } \\
\text { Movement looks abrupt when marked by sudden changes } \\
\text { in subject and sharp transitions }\end{array}$ & $\begin{array}{l}\text { - Abnormally rhythmic movements sometimes } \\
\text { related to seizures occurring in utero } \\
\text { - Activity of flexor muscles will depend on the upper } \\
\text { system since } 34 \mathrm{GWs} \text { or so } \\
\text { - The absence of active head flexion is one of the major } \\
\text { neurological sign at } 40 \text { gestational weeks (GWs) }\end{array}$ \\
\hline $\begin{array}{l}\text { Overlapping cranial sutures and } \\
\text { head circumference }\end{array}$ & $\begin{array}{l}\text { Normal } \\
\text { Cranial sutures not overlapping, smooth, ridges not visible } \\
\text { Abnormal } \\
\text { Cranial ridges over each suture or restricted to the squamous } \\
\text { suture.An abnormally HC is defined as measurement } \\
<2 \text { standard deviations of the normal mean for gestation }\end{array}$ & $\begin{array}{l}\text { - Abnormal cranial ridges over each suture and } \mathrm{HC} \\
\text { below normal limit are related to severe or moderate } \\
\text { impairment of hemispheric growth }\end{array}$ \\
\hline Isolated eye blinking & $\begin{array}{l}\text { Normal } \\
\text { A reflex that closes and opens the eyes rapidly by } \\
\text { involuntary normal periodic closing or by voluntary } \\
\text { action } \\
\text { Movement looks fluent, smooth and unconstrained } \\
\text { Abnormal } \\
\text { Very rare or jerky movements of eyelids during observation }\end{array}$ & $\begin{array}{l}\text { - The presence of this movement indicated absence of } \\
\text { CNS depression } \\
\text { - Visual function is mediated through subcortical } \\
\text { pathway until } 2 \text { months postnatally }\end{array}$ \\
\hline
\end{tabular}


Contd...

\begin{tabular}{ll}
\hline \multicolumn{1}{c}{ Parameter } & \multicolumn{1}{c}{ Observation } \\
\hline $\begin{array}{l}\text { Facial alteration (grimace or } \\
\text { tongue expulsion) }\end{array}$ & $\begin{array}{l}\text { Normal } \\
\text { The wrinkling of the brows or face in frowning, } \\
\text { sometimes characterized by expulsion of the tongue } \\
\text { Abnormal } \\
\text { Almost absent mimic of the face or very rare movements. }\end{array}$ \\
& Face looks always the same like a picture \\
Mouth opening (yawning or & $\begin{array}{l}\text { Normal } \\
\text { Indicating that the fetus is opening the mouth. Sometimes } \\
\text { consists of displacements of tongue and/or larynx. Yawning } \\
\text { is characterized with prolonged wide opening of the jaws } \\
\text { followed by quick closure, retroflexion of the head and } \\
\text { elevation of the arms. } \\
\text { Abnormal } \\
\text { Absence of movements or very rare movemnts of the tongue } \\
\text { and yawning }\end{array}$
\end{tabular}

Isolated hand and leg movements

\section{Normal}

Rapid or slow movements, and may involve extension, flexion, external and internal rotation, or abduction and adduction of an extremity, without movements in other body parts

\section{Abnormal}

The movement characterized by poor repertoire when the movements do not occur in the complex manner. The movement characterized by cramped when it looks

Hand to face movements

Finger movements and thumb position

Gestalt perception of general movements (GMs) Overall perception of the body and limb movements with their qualitative assessment (fluency, variability and amplitude)

The hand touches the face parts, sometimes with extension and flexion of the fingers

Abnormal

Movement looks abrupt when marked by sudden changes in subject and sharp transitions

\section{Normal}

Thumb outside the fist most of the time, finger movements present

\section{Abnormal}

Neurological sign of the thumb is demonstrated when the adduction of the thumb in a clenched fist is non-reducible. Disturbance in fingers and thumb movements correlated with absence of spontaneous motor activity

\section{Normal}

Synchronized movements showing fluencyand elegance of the movements creating theimpression of complexity and variability

Abnormal

Poor amplitude, variability and fluency of the movements sequence of successive components is monotonous and

- The presence of this movement indicated the absence of CNS depression

- The presence of this movement indicated the absence of CNS depression

- Abnormally rhythmic movements sometimes related to seizures occurring in utero

- Automatic leg movement or walking movement is a precompetent stage, present very early in fetal life and still at birth then diminishing in the first 3 months postnatal

- Apparently, walking movement disappearing but later involved in the automatization of independent walk for the rest of the life. This is a typical example of "change of power" from a lower (brainstem) to a higher (cortical) command

- Abnormally rhythmic movements sometimes related to seizures occurring in utero
- Unilateral side of the clenched fist is a precious orientation in case of infarction of the middle cerebral artery

- This motor activity depends on the lower system up to 30-32 GWs and switches to the upper control later on

- The identification of "CNS depression" during fetal life is based on quality of GMs 
An Attempt to Introduce Neurological Test for Fetus Based on 3D and 4D Sonography

Table 3: Prenatal neurological screening test (KANET)

\begin{tabular}{|c|c|c|c|}
\hline \multirow[t]{2}{*}{ Sign } & \multicolumn{2}{|c|}{ Score } & \multirow[t]{2}{*}{ Sign Score } \\
\hline & 0 & 1 & \\
\hline Isolated headanteflexion & Abrupt & $\begin{array}{l}\text { Small range ( } 0-3 \text { times of } \\
\text { movements) }\end{array}$ & $\begin{array}{l}\text { Variable in full range, } \\
\text { many alternation } \\
\text { (> } 3 \text { times of movements) }\end{array}$ \\
\hline $\begin{array}{l}\text { Cranial sutures and head } \\
\text { circumference } \\
\text { a }\end{array}$ & $\begin{array}{l}\text { Overlapping of } \\
\text { cranial sutures head } \\
\text { circumference below or } \\
\text { above the normal limit } \\
\text { (-2SD) according to GA }\end{array}$ & $\begin{array}{l}\text { Normal cranial sutures normal } \\
\text { head circumference }\end{array}$ & \\
\hline Isolated eye blinking & Not present & $\begin{array}{l}\text { Not fluent } \\
\text { (1-5 times of blinking) }\end{array}$ & $\begin{array}{l}\text { Fluency } \\
\text { (> } 5 \text { times of blinking) }\end{array}$ \\
\hline $\begin{array}{l}\text { Facial alteration (grimace } \\
\text { or tongue expulsion) }\end{array}$ & Not present & $\begin{array}{l}\text { Not fluent } \\
\text { (1-5 times of alteration) }\end{array}$ & $\begin{array}{l}\text { Fluency } \\
\text { ( }>5 \text { times of alteration) }\end{array}$ \\
\hline $\begin{array}{l}\text { Mouth opening (yawning or } \\
\text { mouthing) }\end{array}$ & Not present & $\begin{array}{l}\text { Not fluent } \\
\text { (1-3 times of alteration) }\end{array}$ & $\begin{array}{l}\text { Fluency } \\
\text { ( }>3 \text { times of alteration) }\end{array}$ \\
\hline Isolated hand movement & Cramped & Poor repertoire & Variable and complex \\
\hline Isolated leg movement & Cramped & Poor repertoire & Variable and complex \\
\hline Hand to face movements & Abrupt & $\begin{array}{l}\text { Small range } \\
\text { (0-5 times of movement) }\end{array}$ & $\begin{array}{l}\text { Variable in full range, } \\
\text { many alternation } \\
\text { (> } 6 \text { times of movements) }\end{array}$ \\
\hline Fingers movements & $\begin{array}{l}\text { Unilateralor bilateral } \\
\text { clenched fist } \\
\text { (neurological thumb) }\end{array}$ & $\begin{array}{l}\text { Cramped invariable finger } \\
\text { movements }\end{array}$ & $\begin{array}{l}\text { Smooth and complex, } \\
\text { variable finger movements }\end{array}$ \\
\hline Gestalt perception of GMs & Definitely abnormal & Borderline & Normal \\
\hline
\end{tabular}

Total score 
Table 4 was made arbitrary and it represents allocation of fetuses into three separate risk groups for neurological disordes according to KANET.

Table 4: Allocation of fetuses according to KANET

\begin{tabular}{ll}
\hline Total score & Interpretation \\
\hline $0-5$ & Abnormal \\
$6-13$ & Borderline \\
$14-19$ & Normal \\
\hline
\end{tabular}

Basic biometrical and Doppler measurments were taken as well; they are presented in Table 5.

Table 5: Biometrical and Doppler measurements

\begin{tabular}{llllll}
\hline $\begin{array}{l}\text { Biometrical } \\
\text { measurements }\end{array}$ & $\begin{array}{l}\text { Biparietal } \\
\text { diameter }\end{array}$ & $\begin{array}{l}\text { Femur } \\
\text { length }\end{array}$ & $\begin{array}{l}\text { Abdominal } \\
\text { circumference }\end{array}$ & $\begin{array}{l}\text { Head } \\
\text { circumference }\end{array}$ & $\begin{array}{l}\text { Amniotic } \\
\text { fluid index }\end{array}$ \\
\hline $\begin{array}{l}\text { Doppler } \\
\text { measurements }\end{array}$ & $\begin{array}{l}\text { Umbilical } \\
\text { artery }\end{array}$ & Midcerebral artery & & \\
\hline
\end{tabular}

\section{CONCLUSION}

Despite medical reports from 100 years ago and 25 years of systematic research initiated by Prechtl and colleagues, the study of prenatal behavior is still in its infancy. One of the most promising advances in the field of ultrasonography has been the new 4D-US technology. Its advance has been completed in giving visualizations in almost real-time. The availability of new diagnostic data has in an extraordinary way raised our knowledge about intrauterine life, substantially modifying some earlier interpretations.

The 4D study of fetal behavior provided us with a great possibility of understanding the hidden function of the developmental pathway of the fetal CNS and the potentialities of originating a neurological investigation in utero. Now, by 4D technology, we might be able to visualize an intrauterine neurological condition that would enable to identify which fetus is at risk and which is not. Existence of motoric competence in the newborn, even preterm infants is assumed to have its origins in prenatal life. Behavioral perinatology assessed by 4D sonography should be an interdisciplinary area of research involving concepts and conducting studies of the dynamic interplay between behavioral processes in fetal, neonatal, and infant life. The ultimate clinical application of fetal neurobehavioral assessment will be to identify functional characteristics of the fetus that predict a range of subsequent developmental dysfunction. Establishing this link will require demonstration of positive and negative predictability to outcome significantly beyond the immediate perinatal period. After standardization of valid reference ranges of movements appropriate for the gestational age, attempts have been made to produce a new scoring system for fetal neurobehavior based on prenatal assessment by 3D/4D sonography. That preliminary work may help in detecting fetal brain and neurodevelopmental alterations due to in utero brain impairment that is inaccessible by any other method.

\section{REFERENCES}

1. Prechtl HFR. Qualitative changes of spontaneous movements in fetus and preterm infant are a marker of neurological dysfunction. Early Hum Dev 1990;23:151-58.

2. Kurjak A. The beginning of human life and its modern scientific assessment. Clin Perinatol 2003;30:27-44.

3. Kurjak A, Miskovic B, Andonotopo W, Stanojevic M, Azumendi G, Vrcic H. How useful is $3 D$ and 4D ultrasound in perinatal medicine? J Perinat Med. 2007;3:10-27.

4. Kurjak A, Vecek N, Hafner T, Bozek T, Funduk-Kurjak B, Ujevic B. Prenatal diagnosis: what does four-dimensional ultrasound add? J Perinat Med 2002;30:57-62.

5. Azumendi G, Kurjak A. Three-dimensional and four-dimensional sonography in the study of the fetal face. Ultrasound Rev Obstet Gynecol 2003;3:1-10.

6. Kurjak A, Vecek N, Kupesic S. Four dimensional ultrasound: how much does it improve perinatal practice? In Carrera JM, Chervenak FA, Kurjak A, (Eds): Controversies in Perinatal Medicine, Studies on the Fetus as a Patient. New York: Parthenon Publishing, 2003:222-34.

7. Kurjak A, Carrera J, Medic M, Azumendi G, Andonotopo W, Stanojevic M. The antenatal development of fetal behavioral patterns assessed by four-dimensional sonography. J Matern Fetal Neonatal Med. 2005;17:401-16.

8. de Vries JI, Fong BF. Normal fetal motility: an overview. Ultrasound Obstet Gynecol. 2006;27(6):701-11.

9. de Vries JI, Fong BF. Changes in fetal motility as a result of congenital disorders: an overview. Ultrasound Obstet Gynecol 2007;29:590-99.

10. Lee A. Four-dimensional ultrasound in prenatal diagnosis: leading edge in imaging technology. Ultrasound Rev Obstet Gynecol 2001;1:194-98.

11. Kozuma S, Baba K, Okai T, Taketani Y. Dynamic observation of the fetal face by three-dimensional ultrasound. Ultrasound Obstet Gynecol 1999;13:283-84.

12. Campbell S. 4D or not 4D: that is the question. Ultrasound Obstet Gynecol 2002;19:1-4.

13. Nijhuis JG, ed. Fetal Behavior: Developmental and Perinatal Aspects. Oxford: Oxford University Press,1992.

14. Back SA. Perinatal white matter injury: the changing spectrum of pathology and emerging insights into pathogenetic mechanisms. Ment Retard Dev Disabil Res Rev. 2006;12:129-40.

15. de Vries JIP, Visser GH, Prechtl HF. The emergence of fetal behavior, I. Qualitative aspect. Early Hum Dev 1982;7:301-22 Oxford: Oxford University Press.

16. de Vries JIP, Visser GHA, Prechtl HFR. The emergence of fetal behavior, II. Quantitative aspects. Early Hum Dev 1985;12: 99-120.

17. Nijhuis JG, Prechtl HF, Martin CB Jr, et al. Are there behavioural states in the human fetus? Early Hum Dev 1982;6:177-95. 
18. Arduini D, Rizzo G, Giorlandino C, Valensise H, Dell’Acqua S, Romanini C. The development of fetal behavioural states: a longitudinal study. Prenat Diagn 1986;6:117-24.

19. Prechtl HFR, Einspieler C. Is neurological assessment of the fetus possible? Eur Jour Obstet Gynecol 1997;75:81-84.

20. Andonotopo W, Kurjak A, Kosuta MI: Behavioral of anencephalic fetus studied by 4D sonography. J Matern Fetal Neonatal Med 2005;17:165.

21. Andonotopo W, Stanojevic M, Kurjak A, Azumendi G, Carrera JM. Assessment of fetal behavior and general movements by four-dimensional sonography. Ultrasound Rev Obstet Gynecol 2004;4:103.

22. Shawker TH, Schuette WH, Whitehouse W, Rifka SM. Early fetal movement: a real time ultrasound study. Obstet Gynecol 1980;55:194-98.

23. Goldstein I, Zimmer EA, Tamir A, Peretz BA, Paldi E. Evaluation of normal gestational sac growth: appearance of embryonic heartbeat and embryo body movements using the transvaginal technique. Obstet Gynecol 1991;77:885-88.

24. de Vries JIP. The first trimester. In Nijhuis JG, (Ed): Fetal Behavior, Developmental and Perinatal Aspects. Oxford: Oxford University Press, 1992:3-17.

25. Goto S, Kato TK. Early movements are useful for estimating the gestational weeks in the first trimester of pregnancy. In: Levski RA, Morley P (Eds): Ultrasound '82. Oxford-New York: Pergamon Press 1983: 577-582.

26. Kurjak A, Kupesic S, Banovic I, Hafner T, Kos M. The study of morphology and circulation of early embryo by three-dimensional ultrasound and Power Doppler. J Perinat Med 1999;27:145.

27. Kurjak A, Pooh RK, Merce LT, Carrera JM, Salihagic-Kadic A, Andonotopo W. Structural and functional early human development assessed by three-dimensional and fourdimensional sonography. Fertil Steril. 2005;84(5):1285-99.

28. Kurjak A, Carrera JM, Andonotopo W, Azumendi G, Medic M, Salihagic-Kadic A. Behavioral Perinatology Assessed by FourDimensional Sonography. In Kurjak A, (Ed): Textbook of Perinatal Medicine, Jaypee Brothers Medical Publishers, New Delhi.

29. Roodenburg PJ, Wladimiroff JW, van Es A, Prechtl HF. Classification and quantitative aspects of fetal movements during the second half of normal pregnancy. Early Hum Dev 1991;25:1935 rate patterns at 20-22 weeks. Early Hum Dev 1987;15: 333-48.

30. Salihagic-Kadic A, Medic M, Kurjak A, Andonotopo W, Azumendi G, Hafner T, Milenkovic D. Four-dimensional sonography in the assessment of fetal functional neurodevelopment and behavioral patterns. Ultrasound Rev Obstet Gynecol 2005;5:154-68.

31. Kurjak A, Carrera JM, Stanojevic M, Andonotopo W, Azumendi G, Scazzocchio E, Medic M, Salihagic-Kadic A. The role of 4D sonography in the neurological assessment of early human development. Ultrasound Rev Obstet Gynecol 2004;4:148-59.

32. Andonotopo W, Medic M, Salihagic-Kadic A, Milenkovic D, Maiz N, Scazzocchio E. The assessment of fetal behavior in early pregnancy: comparison between 2D and 4D sonographic scanning. J Perinat Med 2005;33:406-14.

33. Pooh RK, Ogura T. Normal and abnormal fetal hand position and movement in early pregnancy detected by three- and fourdimensional ultrasound. Ultrasound Rev Obstet Gynecol 4: 2004:46.
34. Yigiter AB, Kavak ZN. Normal standards of fetal behavior assessed by four-dimensional sonography. J Matern Fetal Neonatal Med 2006;19(11):707-21.

35. Visser GHA. The second trimester. In Nijhuis JG, (Ed): Fetal Behavior, Developmental and Perinatal Aspects. Oxford: Oxford University Press, 1992:17-26.

36. Kuno A, Akiyama M, Yamashiro C, Tanaka H, Yanagihara T, Hata T. Threedimensional sonographic assessment of fetal behavior in the early second trimester of pregnancy. J Ultrasound Med 2001;20:1271-75.

37. Bots RS, Nijhuis JG, Martin CB Jr, Prechtl HF. Human fetal eye movements: detection in utero by ultrasonography. Early Hum Dev 1981;5:87-94.

38. Sparling JW, Van To! J, Chescheir NC. Fetal and neonatal 1993;I2:97. hand movement. Phys Ther 1999;79:24-39.

39. Sparling JW, Wilhelm IJ, Quantitative measurement of fetal does four-dimensional ultrasound add? J Perinat Med movement: Fetal-Posture and Movement Assessment (F- 2002;30:57-62. PAM), Physical and Occupational Therapy in Pediatrics.

40. Kurjak A, Azumendi G, Vecek N, et al. Fetal hand movements and facial expression in normal pregnancy studied by fourdimensional sonography. J Perinat Med 2003;31(6):496.

41. Kurjak A, Azumendi G, Vecek N, Kupesic S, Solak M, Varga D, Chervenak F. Fetal hand movements and facial expression in normal pregnancy studied by four-dimensional sonography. J Perinat Med 2003;3:496-508.

42. Kurjak A, Stanojevic M, Andonotopo W, Scazzocchio-Duenas E, Azumendi G, Carrera JM. Fetal behavior assessed in all three trimesters of normal pregnancy by four-dimensional ultrasonography. Croat Med J 2005;46:772-80.

43. Kurjak A, Andonotopo W, Hafner T, Salihagic Kadic A, Stanojevic M, Azumendi G, Ahmed B, Carrera JM, Troyano JM. Normal standards for fetal neurobehavioral developmentslongitudinal quantification by four-dimensional sonography. J Perinat Med 2006;34:56-65.

44. Patrick J, Campbell K, Carmichael L, Natale R, Richardson B. Patterns of gross fetal body movements over 24-hours observation intervals during the last 10 weeks of pregnancy. Am J Obstet Gynecol 1982;142:363-71.

45. Prechtl HFR, Fargel JW, Weinmann HM, Bakker HH. Postures, motility and respiration of low risk preterm infants. Dev Med Child Neurol 1979;21:3-27.

46. Awoust J, Levi S. New aspects of fetal dynamics with a special emphasis on eye movements. Ultrasound Med Biol 1984;10: 107-16.

47. Prechtl HFR, Weinmann HM, Akiyama Y. Organization of physiological parameters in normal and neurologically abnormal infants. Neuropaediatric 1969;1:101-29.

48. Nijhuis JG, Martin CB Jr, Gommers S, Bouws P, Bots RS, Jongsma HW. The rhythmicity of fetal breathing varies with behavioural state in the human fetus. Early Hum Dev 1983;9:1-7.

49. Kurjak A, Azumendi G, Andonotopo W, Salihagic-Kadic A. Three- and four-dimensional ultrasonography for the structural and functional evaluation of the fetal face. Am J Obstet Gynecol 2007;196:16-28.

50. Merz E, Weber G, Bahlmann F, Miric- Tesanic D. Application of transvaginal and abdominal three-dimensional ultrasound for the detection or exclusion of malformations of the fetal face. Ultrasound Obstet Gynecol 1997; 9:237-43. 
51. Stoll C, Clementi M. Prenatal diagnosis of dysmorphic syndromes by routine fetal ultrasound examination across Europe. Ultrasound Obstet Gynecol 2003;21:543-51.

52. Kurjak A, Stanojevic M, Azumendi G, Carrera JM. The potential of four-dimensional (4D) ultrasonography in the assessment of fetal awareness. J Perinat Med. 2005;33:46-53.

53. De Meyer V, W Zemen, CG Palmer: The face predicts the brain: diagnostic significance of medial facial anomalies for holoprosencephaly (arhinencephaly). Pediatrics 34 (1964) 256.

54. Yan F, Dai SY, Akther N, Kuno A, Yanagihara T, Hata T. Fourdimensional sonographic assessment of fetal facial expression early in the third trimester. Int J Gynaecol Obstet. 2006;94:108-13.

55. Awoust J, Levi S. Neurological maturation of the human fetus. Ultrasound Med Biol 1983;9:583-87.

56. Inoue M, Koyanagi T, Nakahara H. Functional development of human eye-movement in utero assessed quantitatively with realtime ultrasound. American Journal of Obstetric and Gynecology 1986;155:170-74.

57. Parmelee AH, Stern E. Development of states in infants. In: Clemente CD, Purpura DP, Mayer FE, (Eds): Sleep and the Maturing Central Nervous System. New York: Academic Press; 1972. pp 100-215.

58. HFR Prechtl. How can we assess the integrity of the fetal nervous system?

59. Einspieler C, HFR Prechtl, AF Bos, F Ferrari, G Cioni: Prechtl’s method on the qualitative assessment of general movements in preterm, term and young infants. Mac Keith Press, London 2004.

60. Amiel-Tison C: Clinical assessment of the infant nervous system. In: MI Levene, FA Chervenak, M Whittle: Fetal and Neonatal Neurology and Neurosurgery. 3rd ed. Churchill Livingstone, London 2001.

61. Sarnat HB: Functions of the corticospinal and corticobulbar tracts in the human newborn. J Pediatr Neurol 1 (2003) 3.

62. Horimoto N, Koyanagi T, Maeda H, Satoh S, Takashima T, Minami T, Nakano H. Can brain impairment be detected by in utero behavioural patterns? Arch Dis Child. 1993;69:3-8.

63. Morokuma S, Fukushima K, Yumoto Y, Uchimura M, Fujiwara A, Matsumoto M, Satoh S, Nakano H. Simplified ultrasound screening for fetal brain function based on behavioral pattern. Early Hum Dev. 2007;83:177-81.

64. Kurjak A, Stanojevic M, Andonotopo W, Salihagic-Kadic A, Carrera JM, Azumendi G. Behavioral pattern continuity from prenatal to postnatal life-a study by four-dimensional (4D) ultrasonography. J Perinat Med. 2004;32:346-53.

65. DiPietro JA, Bronstein MH, Costigan KA, et al. What does fetal movement predict about behavior during the first two years of life? Dev Psychobiol 2002;40:358-71.

66. DiPietro JA, Hodgson DM, Costigan KA, Johnson TR et al. Fetal antecedents of infant temperament. Child Dev 1996;67:2568-83.

67. DiPietro JA, Costigan KA, Pressman EK. Fetal state concordance predicts infant state regulation. Early Hum Dev 2002;68:1-13.

68. St James-Roberts I, Menon-Johansson P. Predicting infant crying from fetal movement data: an exploratory study. Early Hum Dev 1999;54:55-62.

69. Back SA. Perinatal white matter injury: the changing spectrum of pathology and emerging insights into pathogenetic mechanisms. Ment Retard Dev Disabil Res Rev 2006;12: 129-40.

70. Back SA, Riddle A, McClure MM. Maturation-dependent vulnerability of perinatal white matter in premature birth. Stroke. 2007;38:724-30.

71. Bax M, Goldstein M, Rosenbaum P, Leviton A, Paneth N, Dan B, Jacobsson B, Damiano D; Executive Committee for the Definition of Cerebral Palsy et al. Proposed definition and classification of cerebral palsy, April 2005. Dev Med Child Neurol. 2005; 47:571-76.

72. Bax M, Goldstein M, Rosenbaum P, Leviton A, Paneth N, Dan B, et al. Proposed definition and classification of cerebral palsy, April 2005. Dev Med Child Neurol 47 (2005) 571.

73. Rosenbaum P, Paneth N, Leviton A, Goldstein M, Bax M, Damiano D, Dan B, Jacobsson B. A report: the definition and classification of cerebral palsy. Dev Med Child Neurol. 2007;109:8-14.

74. Palmer FB. Strategies for the early diagnosis of cerebral palsy. J Pediatr. 2004;145:8-11.

75. Gosselin J, Amiel-Tison C, Infante-Rivard C, Fouron C, Palmer FB. Strategies for the early diagnosis of cerebral palsy. J Pediatr 2004;145: 8-11.

76. Pooh RK, K Maeda, KH Pooh: Acquired brain abnormalities in utero. In: Pooh RK, K Maeda, KH Pooh: An Atlas of Fetal Central Nervous System Disease - Diagnosis and Management. Parthenon, New York 2003.

77. Pooh RK, KH Pooh. Congenital brain anomalies. In: Pooh RK, K Maeda, KH Pooh: An Atlas of Fetal Central Nervous System Disease - Diagnosis and Management. Parthenon, New York 2003.

78. Amiel-Tison C, RN Laurini: Fetal and perinatal brain damage: a clinicopathological correlation. In: Kurjak A: Textbook of Perinatal Medicine. Parthenon, London 1998.

79. Kostovic I, M Judas, M Rados, P Hrabac: Laminar organization of the human fetal cerebrum revealed by histochemical markers and MRI. Cereb Cortex 12 (2002) 536.

80. Hepper PG: Fetal habituation: another Pandora's box? Dev Med Child Neurol 39 (1997) 274.

81. Strijbis EMM, Oudman I, van Essen P, MacLennan AH. Cerebral palsy and the application of the international criteria for acute intrapartum hypoxia. Obstet Gynecol. 2006;107:1357-65.

82. Kurjak A, Miskovic B, Stanojevic M, Amiel-Tison C, Ahmed B, Azumendi G, Vasilj O, Andonotopo W, Turudic T, SalihagicKadic A. New scoring system for fetal neurobehavior assessed by three- and four-dimensional sonography. J Perinat Med. 2008;36(1):73-81.

83. Amiel-Tison C. Neurological assessment of the neonate revisited: a personal view. Dev Med Child Neurol. 1990;32: 1105-13.

84. Amiel-Tison C, Gosselin J, Kurjak A. Neurosonography in the second half of fetal life: a neonatologist's point of view. J Perinat Med. 2006;34:437-46.

85. Hata T, Kanenishi K, Akiyama M, Tanaka H, Kimura K. Realtime 3-D sonographic observation of fetal facial expression. J Obstet Gynaecol Res. 2005;3:337-40.

86. Salihagic-Kadic A, Kurjak A, Medić M. Andonotopo W, Azumendi G. New data about embryonic and fetal neurodevelopment and behavior obtained by 3D and 4D sonography. J Perinat Med. 2005;33:478-90. 